\title{
Da utilidade e uso das fórmulas químicas. Laurent versus Gerhardt
}

\section{Introdução}

Histórica e conceitualmente, as formulas químicas sempre pretenderam ser a expressão mais simples da composição das substâncias que representam e dos processos que entre elas podem ocorrer. O seu desenvolvimento tem raízes que entrosam nos antigos símbolos cabalísticos que serviam para rotular os recipientes cerâmicos e/ou de vidro usados, desde a mais remota antiguidade, no armazenamento dos diversos produtos químicos.

Consideradas, todavia, do ponto de vista da sua representação lógica quantitativa, e do ponto de vista do seu conteúdo simbólico e informativo, as fórmulas quimicas não contam ainda com dois séculos de história (ref. 1).

Quer a Tabela de Becher (1635-1682) composta por dez simbolos representativos de outros tantos grupos distintos de substâncias (minerae, metalla, mineralia, salia, decomposita, terrae, destillata, olea, limi e compositiones), quer a famosa Tabela de Afinidades da autoria de Geoffroy (1672-1713) aparecida em 1718, cujo objectivo era dar aos estudantes ".... en peu de temps, une juste idée du rapport que les différents substances ont les unes avec les autres" (ref. 2), embora de grande utilidade para grande número de químicos de Macquer (1718-1784) a Bergman (1735-1784) que delas fizeram extensivo uso, já pelos símbolos usados, já pelas afinidades apontadas, estão longe de se aparentarem legitimamente com o conteúdo científico programaticamente carreado pelo Projecto em que se viria a traduzir o recurso às fórmulas químicas.

Os cadernos de laboratório de Scheele (1742-1786) estão cheios de símbolos a que o seu autor recorria para descrever, sucinta e abreviadamente, a preparação dos mais diversos produtos químicos; todavia, nas suas publicaçðes, nunca Sheele usou quaisquer tipos de símbolos.

E sabe-se que uma das preocupaçðes constantes de Lavoisier (1743-1794) na elaboração das suas Comunicaçð̄es químicas foi dar-lhes a maior precisão matemática possível. Ressoavam, certamente, em seus ouvidos, as observaçס̃es de Kant que, em 1786, negava categoricamente a possibilidade de a química ser susceptível dum tratamento matemático e dedutivo, afirmando que, por isso mesmo, nunca ela poderia ser mais que uma arte engenhosa, uma ciência experimental, mas nunca uma verdadeira ciência. No intuito "d'appliquer l'exactitude du calcul a la Chemie"' (ref. 3, pg. 492), Lavoisier tentou conferir aos símbolos químicos que recebera do passado e a alguns outros de sua própria lavra, um conteúdo significativo que exprimisse relaçð̋es quantitativas. Confessava, contudo, com a clareza própria de quem sabia quanto havia ainda para fazer neste domí- nio: "estamos ainda muito longe de conferir à química a precisão matemática desejada e, consequentemente, peço que as formulas químicas que usei sejam consideradas apenas como simples anotaçðes, cujo objectivo é facilitar as operaçðes da mente" (ref. 3, pg. 499).

Em 1787, na sequência dos trabalhos de Lavoisier, Hassenfratz (1755-1827) e Adet (1763-1832) tentaram dar à notação química uma forma mais clara e uniforme, recorrendo a caracteres geométricos e a símbolos alfabéticos derivados dos nomes latinos, inscritos em círculos, para representação mais fácil dos elementos conhecidos e suas combinaçø̃es. A falta de fluidez de escrita de que se revestia esta notação não a tornou, porém, particularmente popular, não obstante a recomendação favorável ao seu uso emitida por uma Comissão especializada da Academia Francesa de que fez parte o proprio Lavoisier (ref. 4). Outro tanto aconteceria com a notação usada, tempos depois, por Dalton (1766-1844), pese embora a informação qualitativa e quantitativa que traduzia, relativamente à composição dos compostos representados.

Deste modo, é com o sueco Berzélius (1779-1848) que as formulas químicas se revestem essencialmente do conteúdo informativo que as caracteriza ainda hoje. A primeira referência à notação de Berzélius data de Janeiro de 1814, nos Annals of Philosophy de Thomson, sob o título sobre símbolos químicos e sobre o método de os usar para exprimir proporçðes químicas. O próprio Berzélius definiu com clareza o objectivo que se propunha com a notação química que apresentava:

"Devo observar aqui que o objectivo dos novos símbolos não é, como acontecia com os símbolos químicos até aqui usados, o seu uso para rotular recipientes no laboratório; destinam-se tão somente a facilitar $a$ expressão das proporçóes químicas, e a possibilitar-nos a indicação, sem grandes perífrases, do número relativo de volumes dos diferentes constituintes contidos em cada corpo composto. Indicando o peso dos volumes elementares, estes símbolos permitir-nos-ão exprimir os resultados numéricos de uma análise duma maneira tão simples, e de fácil memorização, quanto as fórmulas algébricas da filosofia mecânica" (ref. 5).

Ao longo de todo o infatigável trabalho que a partir daqui dispendeu ao serviço da química, Berzélius sentiu sempre uma crescente necessidade de aperfeiçoar e simplificar o mais possível a notação química com que começara, de modo a servir melhor o ideal que com ela se propusera. É a partir de propostas suas que será despoletada a polémica entre Gerhardt (1816-1856) e

a Departamento de Quimica, Universidade de Coimbra, 3000 Coimbra. 
Laurent (1808-1853) sobre o tipo de formulas químicas mais conveniente. A ela faremos referência mais abaixo.

\section{Das fórmulas empíricas às fórmulas de projecção}

Em 1826, ao publicar nova Tabela de pesos atómicos, Berzélius sentiu necessidade de alterar vários símbolos que até então usara, e também a necessidade de alterar alguns dos índices numéricos, que acompanhavam tais simbolos. Concretamente, dividiu todos esses indices numéricos por 2 ou 4 para que as fórmulas apresentadas ficassem de harmonia com a lei dos calores atómicos de Dulong-Petit e com a lei do isomorfismo de Mitscherlich. Era o reconhecimento público de que as fórmulas químicas se podiam apresentar em mais que uma forma.

Rapidamente se evidenciou o diverso conteúdo informativo comportado por diferentes formas possiveis e, surpreendentemente, muito em breve se assistia a um terçar de armas pela defesa do uso de umas de preferência, ou mesmo em desprimor, a outras.

A fórmula empírica ou proporcional de uma substância ficava-se pela representação mais simples da mesma, limitando-se a referir os elementos componentes e os números relativos, na forma dos menores números inteiros possíveis, dos átomos desses elementos.

Com a determinação de pesos moleculares, logo se reconheceu que nem sempre a fórmula empirica representava o mais satisfatoriamente possível a substância a que se referia, e logo se avançou para o estabelecimento de formulas moleculares.

Com o desenvolvimento da teoria atómica e a tentativa de compreensão do arranjo possivel dos átomos entre si na constituição duma substância, seriam definidas as formulas estruturais, racionais ou constitucionais em que é patente o desejo de informar sobre as ligaçőes entre os diferentes átomos (quais átomos se ligam a quais) e sobre o tipo dessas ligaçס̄es (simples, duplas, triplas). E destas se evoluiria quase naturalmente para as chamadas formulas configurais ou formulas espaciais, com sua tradução específica em fórmulas de projecção, onde há não só informação sobre o número de átomos de cada um dos elementos presentes na molécula da substância que representam, como também sobre o modo como esses átomos estão ligados entre si, e sobre as posiçðes espaciais relativas dos mesmos (ref. 6).

Não obstante o crescente conteúdo informativo subjacente a esta evolução de um tipo de formulas para outro, a sua aceitação não foi pacífica, nem foi tida como óbvio progresso. Disso é testemunho clarividente a polémica em que se debateram, nos ans quarenta do século passado, os dois químicos Gehardt e Laurent, colegas, amigos e co-fundadores de Comptes Rendus Mensuels des Travaux Chimiques de L'Étranger (ref. 7).

\section{Charles Gerhardt vs. Augusto Laurent}

$\mathrm{Na}$ sequência da descoberta do isomorfismo e do isomerismo, particularmente na sequência dos seus estudos sobre o ácido tartárico, Berzélius havia notado que tudo se passava como se "os simples átomos de que as substâncias eram compostas se pudessem unir uns com os outros de diversos modos" (ref. 8). Consequentemente, as fórmulas empíricas e moleculares não seriam de per si representação suficiente e cabal de um composto. $\mathrm{O}$ acetato de metilo era absolutamente diferente do formato de etilo e no entanto a ambos correspondia a mesma fórmula empírico-molecular!

A confusão que então reinava no dominio da teoria atómica e o uso e abuso que os químicos faziam dos incipientes conceitos por ela avançados, faziam, todavia, que reinasse o maior dos ceptimismos quanto à possibilidade de se poder conhecer as posiçðes ocupadas pelos diversos átomos na constituição de uma dada molécula. Augusto Comte resumiu a atitude então reinante entre muitos químicos nesta matéria, com as seguintes palavras: "o modo real da aglomeração das partículas elementares é, e sê-lo-á sempre, totalmente desconhecido para nós e não é, consequentemente, objecto adequado para o nosso estudo" (ref. 9).

Dominado por este tipo de cepticismo, Gerhardt, no seu tratado Précis de Chimie Organique de 1844-5, atacou duramente as formulas racionais propostas por Berzélius, argumentando que só as formulas empiricas eram verdadeiramente importantes. No mesmo tratado, propunha uma classificação dos compostos orgânicos baseada exclusivamente nas fórmulas empiricas, tentando mostrar que as formulas racionais não se revestiam de qualquer interesse (ref. 10).

A esta posição de Berhardt se opôs, imediatamente e com não menos dureza, Laurent, em carta a ele dirigida que viria a ser apenas o princípio de vasta correspondência trocada entre ambos sobre o assunto. Dizia Laurent:

"Na sua classificação, Gerhardt põe de lado as formulas racionais! Sem negar que há nos corpos compostos um certo arranjo dos átomos, do qual dependem as propriedades dos mesmos compostos, ele afirma que nós jamais saberemos qual seja tal arranjo, e que, por consequência, todo o sistema baseado sobre fórmulas racionais será sempre vicioso. Não partilhamos desta opinião de Gerhardt; cremos na existência do grupo amónio; cremos que no sulfato, nitrato, acetato de morfina há um agrupamento morfinico" (ref. 11, pg. 176).

Tentando dissuadir Gerhardt da defesa incondicional e exclusiva das formulas empíricas, Laurent admitia também ele o cepticismo em que o colega se baseava para rejeitar o interesse das formulas racionais, e para o lugar destas propunha um outro sistema de formulas de sua autoria, as chamadas formulas sinópticas.

"Uso um sistema particular de formulas que chamarei sinópticas. Elas têm, penso eu, as vantagens das formulas brutas (=as fórmulas empíricas) e das formulas racionais, sem os inconvenientes nem d'umas, nem d'outras. Não tenho a pretensão de representar com as minhas formulas o arranjo real dos átomos... São, todavia, ideias sobre o arranjo molecular que presidem ao sistema que exponho; contudo, querendo, pode abstrair-se delas e não ver nas fórmulas que proponho senão símbolos cujo aspecto lembra imediatamente, não apenas a composição e a natureza dos corpos que representam, mas também a série a que tais corpos pertencem e o lugar que devem ocupar dentro da mesma" (ref. 12).

"Embora não pretendamos que o arranjo dos átomos é indicado pelas formulas, queremos dizer muito simplesmente que se $\mathrm{o}$ ácido acético $=\mathrm{C}^{8} \mathrm{H}^{8}+\mathrm{O}^{4}$, o ácido formico deverá ser $\mathrm{C}^{4} \mathrm{H}^{4}+\mathrm{O}^{4}$ "' (ref. 11, pg. 41).

"Uso as formulas sinópticas como um meio de indicar, não o arranjo dos átomos, mas simplesmente as analogias existentes entre certas classes de corpos. Reconhe- 
ço, em acordo com o resto do mundo, que o nitrato amoniacal é um nitrato; consequentemente, se represento o nitrato de potássio por $\mathrm{KNO}^{3}$, devo dar ao nitrato de amónia uma formula semelhante, a saber, $\mathrm{NH}^{4} \mathrm{NO}^{3}$..." (ref. 13, pg. 284).

"Com a ajuda das fórmulas sinópticas esforço-me por manifestar certas relaçōes numéricas que certos corpos duma mesma série apresentam, e por representar corpos análogos com fórmulas análogas" (ref. 13, pg. 348).

Mas Gerhardt não era fácil de convencer. Continuava a usar somente as formulas empíricas, opondo-se renitentemente à expansão do uso das fórmulas racionais. O seu Traité de Chimie Organique (ref. 14), editado cerca de dez anos depois do Précis de Chimie Organique, mantém a posição inicialmente assumida:

"Em resumo, as fórmulas químicas não exprimem, nem podem exprimir senão relaçōes, analogias; as melhores serão aquelas que tornem sensíveis o maior número de relaçōes, o maior número de analgias...

"Este carácter das fórmulas químicas torna evidentemente ociosas todas as dicussð̃es que se centrem exclusivamente sobre a questão de saber sob que forma um dado elemento ou grupo de elementos está envolvido numa combinação, que dela se possa extrair ou nela se possa introduzir, caso não associe a essa forma uma ideia precisa de reacçōes ou propriedades químicas. Concebo que se diga de certos corpos azotados que possuem o azoto sob a forma de vapor nitroso $\mathrm{NO}^{2}$ para significar que o azoto foi neles introduzido a partir do ácido nítrico, para significar que explodem sob a acção do calor como acontece com os nitratos, ou, ainda, para significar que se reduzem sob a acção do sulfureto de hidrogénio, etc..."' (ref. 14, pg. 563).

Note-se que quando Gerhardt afirma que "as melhores fórmulas serão aquelas que tornem sensíveis o maior número de relaçð̋es, o maior número de analogias"' subentende expressamente que essas formulas são as fórmulas empíricas já que sendo estas as mais simples são, correlativamente, as mais universais. À maior simplicidade corresponde a maior universalidade.

"As fórmulas químicas não se destinam a representar o arranjo real dos átomos; o seu objectivo, é sim, tornar evidentes, da maneira mais simples e mais exacta possivel, as relaçōes que interligam os diferentes corpos entre si, sob o aspecto das respectivas transformaçð̄es. "Toda a transformação, toda a reacção química, pode ser representada por uma equação entre as matérias reagentes e os produtos. Representar um corpo por uma formula racional é resumir por sinais convencio- nais um certo número de equaçð̄es em que esse corpo figura, tomando para unidade de comparação um outro corpo. Deste modo, as formulas racionais são de alguma maneira equaçøes contractas (ref. pg. 566).

"Quando um mesmo reagente é posto em contacto com diferentes agentes capazes de o levarem a decompor-se de modos diferentes, acontece frequentemente que esse reagente não apresenta a cada um desses agentes o mesmo lado para o ataque; a decomposição múltipla pode então efectuar-se em sentidos diferentes. Uma matéria orgânica que se comporte desta maneira pode, portanto, ser representada por várias formulas racionais"' (ref. 14, pg. 577).

Quer dizer, o uso das formulas racionais, além de restritivo, prestar-se-ia também a um desseminar do equívoco na formulação de muitas afirmaçōes científicas, uma situação de todo em todo indesejável.

Esta querela entre Gerhardt e Laurent sobre o interesse ou não-interesse do uso de outras formulas químicas que não as formulas empíricas só contribuiu para melhor definir qual deveria ser o conteúdo informativo das formulas químicas. Dela saiu reforçada a posição de Berzélius sobre a necessidade de avançar para além da simples formula empírico-molecular. Muito rapidamente, o desenvolvimento do conceito de valência viria dar um sentido mais profundo às ideias discutidas pelos dois químicos. A formula proposta por Kekulé (1829-1896) para o benzeno e seus derivados seria passo determinante no ultrapassar da querela. Com a criação da estereoquímica por Van't Hoff (1852-1911) e Le Bel (1847-1930) era chegada a idade-adulta do simbolismo traduzido pelas fórmulas químicas que com Berzélius iniciara a sua meninice. A querela entre Gerhardt e Laurent mais não fora que uma fase de seu crescimento.

\section{BIBLIOGRAFIA}

(1) R. Winderlich, J. Chem. Educ., 30, 58 (1953).

(2) E.F. Geoffroy, Table des différents rapports observés en chimie entre différents substances, Mémoires de l'Academie Royale, Paris, 1718; Amsterdam, reurint, 1723, pg. 256.

(3) A.L. Lavoisier, Mémoires Acad. Paris, 1782, pg. 492.

(4) A.L. Lavoisier, Ouevres, Tom. V, Paris. 1892, pp. 365-375.5.

(5) J.J. Berzélius,' Thomson's Annals of Philosophy, 3, 51 (1814).

(6) R.L. Bent, J. Chem. Educ., 30, 220 (1953).

7. O. Potter, British J. Phil. Sci., 3, 359 (1952).

(8) J.J. Berzélius, Jahresbericht, 11, 44 (1832).

(9) I.A.M. Comte, Cours de Philosophie Positive, Paris, 1830-42, vol. 3, pg. 115 .

(10) C.F. Gerhardt, Précis de Chimie Organique, Paris, 1844-5.

(117 Correspondance de Charles Gerhardi, Ed. M. Tiffeneau, Paris, 1918 .

(12) A. Laurent, Comptes Rendus, 18, 1098 (1844).

(13) A. Laurent, Chemical Method, Londres, 1855.

(14) C.F. Gerhardt, Traité de Chimie Organique, Paris, 1853-6, Tom. IV. 


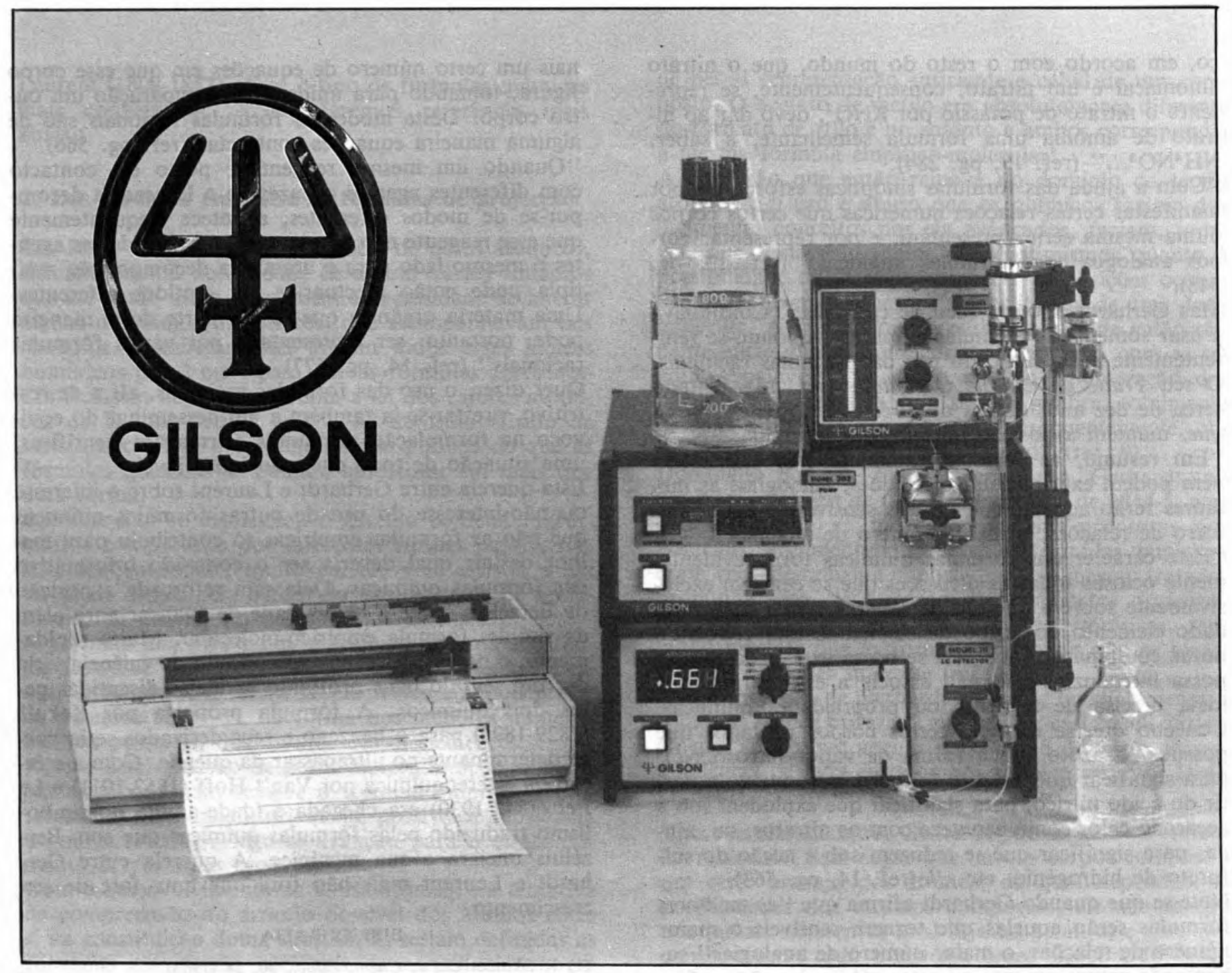

\section{SISTEMA DE HPLC ISOCRÁTICO ANALÍTICO}

COMPRE O SISTEMA DE HPLC À MEDIDA DAS SUAS NECESSIDADES.

COMECE COM UM SISTEMA BÁSICO ISOCRÁTICO E VÁ-LHE ACRESCENTANDO OUTROS MÓDULOS ATÉ AO MAIS COMPLETO E SOFISTICADO SISTEMA AUTOMÁTICO DE GRADIENTE TERNÁRIO.

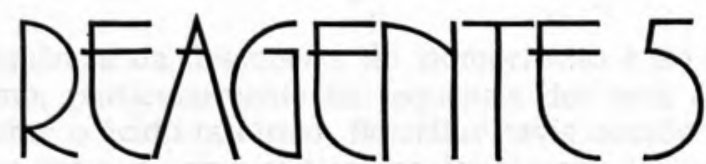

RUA DAMIAOO DE GOIS, 358

APARTADO 710 - 4012 PORTO CODEX - PORTUGAL

TELEFONES: 486185-486698 - TELEX 28167 REQUEL

RUA SOARES DOS REIS, 26 - TELEF. 691627 - 1100 LISBOA 